REVISTA DE DERECHO UNED, NÚM. 11, 2012

\title{
LAS NUEVAS TECNOLOGÍAS Y LA GARANTÍA PROCESAL DE LAS LIBERTADES
}

\author{
NEW TECHNOLOGIES AND THE PROCEDURAL \\ GUARANTEE OF LIBERTIES
}

ENRIQue CÉSAR PÉREZ-Luño Robledo

Profesor del Instituto Andaluz Interuniversitario de Criminología

(Sevilla)

Recepción original: 01/11/2012

Aceptación original: 05/11/2012

Sumario: I. Planteamiento: La garantía procesal de los derechos ante el reto tecnológico; II. La acción procesal de habeas data; III. Las garantías procesales y las generaciones de derechos humanos; IV. La protección jurisdiccional de las libertades en la sociedad tecnológica; V. Conclusión.

\section{PLANTEAMIENTO: LA GARANTÍA PROCESAL DE LOS DERE- CHOS ANTE EL RETO TECNOLÓGICO}

El impacto de las nuevas tecnologías (NT) y de las tecnologías de la información y de la comunicación (TIC) en el ámbito de los derechos humanos ha sido objeto de una atención creciente en la legislación, la jurisprudencia y la doctrina de nuestro tiempo. Una de las respuestas más relevantes, desde el punto de vista jurídico, al desafío tecnológico a las libertades, ha sido la propiciada por nuevos instrumentos de garantía procesal tendentes a dotar a los ciudadanos de medios adecuados para la protección jurídica de su status cívico.

En el conjunto de normas procesales referentes a la regulación de distintos aspectos de la utilización de medios tecnológicos y de sus 
consecuencias jurídicas, destacan nuevas modalidades de garantías. En este sector jurídico posee una especial importancia todo el conjunto de normas procesales encaminadas a la tutela de los derechos fundamentales frente a eventuales abusos informáticos, así como las normas procesales civiles y penales encaminadas a regular las acciones judiciales tendentes a la reparación de los actos ilícitos o de los crímenes informáticos, especialmente, de aquellos referentes a la lesión de derechos fundamentales.

En el seno de los medios de tutela de las libertades frente a agresiones informáticas, destaca en el Derecho comparado y en nuestro propio sistema jurídico, la acción procesal del habeas data. Mediante ella se ejercitan los cauces procedimentales a través de los que los ciudadanos concernidos por informaciones contenidas en archivos o bancos de datos informatizados, pueden tener acceso a las mismas con el fin de ejercer sus facultades de información y de control de dichas informaciones.

\section{LA ACCIÓN PROCESAL DE HABEAS DATA}

Entre el arsenal de instrumentos procesales tendentes a garantizar el ejercicio de los derechos fundamentales en la sociedad tecnológica, destaca la denominada acción procesal de «habeas data». Esta expresión se inspiró en la terminológicamente en la institución del habeas corpus, acción procesal tendente a garantizar la libertad física de las personas frente a detenciones arbitrarias. La analogía terminológica existente entre las expresiones «habeas corpus y «habeas data no es arbitraria ni casual. En las consideraciones subsiguientes se intentará ofrecer algunos argumentos en los que se haya fundamentada dicha analogía.

Se ha indicado que: "Aludir a un tránsito desde el habeas corpus al habeas data, representa aceptar, de forma implícita, que existe una evolución de los derechos y libertades, o, si se prefiere, que estamos asistiendo a un proceso evolutivo de generaciones de derechos humanos (Pérez Luño, 1992, 36).

El habeas data tiende a garantizar a las personas el derecho de acceso a los datos que les conciernen y que han sido registrados en archivos informáticos o bases de datos.

Al perfilar su naturaleza jurídica de esta institución, Rubén Flores Dapkevicius, la caracteriza como una acción procesal consistente: « en el derecho que asiste a toda persona, identificada o identificable, 
a solicitar la exhibición de los registros, públicos o privados, en los cuales están incluidos sus datos personales o los de su grupo familiar, para tomar conocimiento de su exactitud; a requerir la rectificación, la supresión de datos inexactos u obsoletos o que impliquen discriminación por ser sensibles»(Flores Dapkevicius, 2011, 64).

Según Néstor Pedro Sagües el habeas data representa «una pieza del derecho procesal constitucional configurativa de un amparo especializado, con finalidades específicas» (Sagües, 1991, 1035). Se trataría de un procedimiento de amparo referido al acceso, por parte de los ciudadanos a los datos personales que les afectan, como instrumento procesal específico de garantía de la intimidad, a fin de prevenir o evitar abusos informáticos.

La dimensión teleológica del habeas data se cifra en proteger a los titulares de esa acción procesal contra la invasión de su intimidad, en su acepción más amplia que abarca, también a todos los aspectos de la vida privada, del honor y de la imagen de las personas concernidas. Se trata, en definitiva, de una acción dirigida a conocer, acceder, rectificar, suprimir y prohibir la divulgación de determinados datos, ya sea porque han sido indebidamente procesados o porque se pretenda utilizarlos o transmitirlos al margen de la finalidad que legitimaba su registro. De este modo, se pueden evitar también el que, a través de un cruce ilegal de archivos, se puedan elaborar "perfiles de personalidad», evitando así calificaciones discriminatorias o erróneas que puedan perjudicar a la persona a que se refieren los datos (Arenas, 2006, 47ss.; Garriga Domínguez, 1999, 53 ss.; Lucas Murillo de la Cueva, 1990, 187 ss.; Perez Luño, Losano, y Guerrero Mateus, 1989, 43 ss).

\section{LAS GARANTÍAS PROCESALES Y LAS GENERACIONES DE DERECHOS HUMANOS}

En la teoría de los derechos humanos las nuevas categorías procesales dirigidas a su garantía, en las sociedades tecnológicas, remite a los nuevos significados y funciones que cumplen los derechos en nuestro tiempo. Esta nueva visión es fruto de sustituir una concepción estática de las libertades por una concepción dinámica o generacional.

El paradigma generacional de los derechos y libertades parte de la evolución histórica de los mismos. De acuerdo con dicho enfoque, se ha producido una mutación histórica de los derechos, la cual ha 
determinado la aparición de sucesivas generaciones de derechos. De conformidad con este paradigma, se sostiene que los derechos y libertades nacen en la Modernidad, son el fruto del pensamiento racionalista ilustrado que inspiró las revoluciones burguesas del siglo XVIII. Ese marco histórico determinará la ideología subyacente a la primera generación de derechos humanos. Se trata de libertades de signo individual, propias de la mentalidad individualista burguesa prevalente en los planteamientos liberales de los modelos de organización política en los que tales derechos alcanzaron su plasmación: los Estados liberales de Derecho.

Ese fundamento individualista sufrirá un amplio proceso de erosión e impugnación en las luchas sociales del siglo XIX. Los movimientos reivindicativos decimonónicos, tales como el movimiento obrero, el socialismo en su pluralidad de manifestaciones, el feminismo, el pensamiento social cristiano, el solidarismo..., exigirán la necesidad de completar el catálogo de los derechos y libertades de la primera generación con una segunda generación de derechos: los derechos económicos, sociales y culturales. Estos derechos alcanzarán su paulatina consagración jurídica y política en la sustitución del Estado liberal de Derecho por el Estado social de Derecho.

En nuestro tiempo ha aparecido una nueva o «tercera generación» de derechos humanos. Estos nuevos derechos se refieren a cuestiones tales como el derecho a la paz, los derechos de los consumidores, el derecho a la calidad de vida y a la protección del medio ambiente, el derecho al desarrollo, la libertad informática con la consiguiente tutela de los datos personales, las garantías frente a determinados usos de las biotecnologías... (Pérez Luño, 2006, 2012; Rodríguez Palop, 2010).

Las NT y las TIC han transformado las relaciones de los seres humanos con la naturaleza, las relaciones de los seres humanos entre sí y la relación del ser humano para consigo mismo (Pérez Luño, 2006, 2012). Estas mutaciones no han dejado de incidir en las técnicas de protección y garantía procesal de los derechos humanos. Se ha producido, de este modo, un fenómeno bifronte: de una parte, las NT y las TIC han producido importantes desarrollos y mejoras en las condiciones vitales de la humanidad, contribuyendo a reforzar, en ocasiones, el disfrute y ejercicio de determinados derechos. Así, por ejemplo, la gestión informatizada de la justicia ha contribuido a hacer más eficaz y transparente la tutela judicial de los derechos y libertades. Pero como reverso a estos avances, determinados usos o abusos tecnológicos han supuesto una grave amenaza para los de- 
rechos fundamentales, lo que ha exigido la formulación de nuevos derechos o actualización y adecuación a los nuevos retos de los instrumentos de garantía de derechos ya existentes.

El habeas data constituye, en suma, un cauce procesal para salvaguardar la libertad de la persona en la esfera informática, que cumple una función paralela, en el seno de los derechos humanos de la tercera generación, a la que en los de la primera generación correspondió al habeas corpus respecto a la libertad física o de movimientos de la persona.

En la doctrina sobre los derechos se sostiene que las distintas libertades ahondan su raíz histórica en previas situaciones de violación o carencia, a cuyo remedio precisamente se dirigen. De ahí, el nexo inmediato de fundamentación antropológicas de los derechos y libertades en el sistema de necesidades humanas básicas o radicales.

Como se ha tenido ocasión de exponer, el habeas corpus surge como réplica frente a los fenómenos abusivos de privación de la libertad física de la persona, que se habían producido en la Antigüedad y el Medioevo proyectándose, a través del absolutismo, hasta las diversas manifestaciones del totalitarismo de nuestros días.

El habeas corpus aparece, por tanto, como una acción procesal por la que se solicita del juez que se dirija al funcionario que tiene una persona detenida y la presente ante él. Se trata, por tanto, de una garantía judicial específica para la tutela de la libertad personal (Martín Ostos, 1983, 1ss.; Soriano, 1986, 73).

Al cotejar las instituciones del habeas corpus y el habeas data se comprueba que existe una inicial coincidencia y una analogía cuanto a la estructura de ambas figuras en lo referente a su naturaleza jurídica, a su objeto y a su finalidad.

1) En lo que concierne a su naturaleza jurídica, debe afirmarse que en ambos supuestos nos hallamos ante acciones procesales dirigidas a la defensa de la libertad. En el caso del habeas corpus se trata de defender la libertad física de las personas, frente a detenciones arbitrarias; mientras que en el supuesto del habeas data la protección jurídica se dirige a la defensa de la libertad informática de los ciudadanos, es decir, a la facultad de acceso a los datos que le conciernen por parte de la persona interesada.

El habeas corpus y el habeas data representan, además, dos garantías procesales de aspectos diferentes de la libertad. Así, mientras el primero se circunscribe a la dimensión física y externa de la libertad, el segundo tiende a proteger prioritariamente aspectos internos 
de la libertad: la identidad de la persona, su autodeterminación, su intimidad, sus datos personales... No debe soslayarse, en efecto, que, en las sociedades informatizadas actuales, también la libre actuación pública de los ciudadanos se halla condicionada por sus posibilidades de acceso a la información.

Pero la diferencia más importante es que el habeas corpus aparece como uno de los mecanismos procesales básicos para defender la libertad en el marco de lo que, en la célebre teoría de los status, elaborada por Georg Jellinek serán el status libertatis y el status civitatis (Jellinek, 1964, 96 ss.) .

En tanto que el habeas data ha sido fruto del proceso de sucesiva ampliación de los status, ya que su reconocimiento ha sido posible en la medida en que ha calado la exigencia de completarlo con nuevos cauces jurídicos que se hicieran cargo de las sucesivas transformaciones operadas en las situaciones subjetivas. Se ha hecho, por tanto, necesario ampliar aquella tipología, pensada para dar cuenta de las libertades y derechos de la primera generación, con el reconocimiento de un status positivus socialis, que se haría cargo de los intereses económicos, sociales y culturales propios de la segunda generación.

En la actualidad la consagración de la libertad informática y el derecho a la autodeterminación informativa, en el marco de los derechos de la tercera generación, han determinado que en el presente el protagonismo adquirido por la jurisdicción constitucional de la libertad, las modalidades de tutela innovadas por las instancias jurisdiccionales internacionales, así como la relevancia que ahora asumen las normas de procedimiento para la organización y realización de los derechos humanos, hace que se aluda a un status activus processualis, una de cuyas principales manifestaciones sería, precisamente, el habeas data.

Erhard Denninger concibe dicho status como el reconocimiento de la facultad de cada persona para participar activamente y asumir su propia responsabilidad en los procedimientos que le afectan, así como en el seno de las estructuras organizativas más directamente vinculadas con el ejercicio de los derechos fundamentales (Denninger, 1987, 268 ss.).

El status activus processualis constituye un factor clave de los Estados de Derecho para asegurar el ejercicio pleno de todas las libertades. Su reconocimiento se desglosa en la garantía de cinco posiciones procesales básicas: a) el derecho a la audiencia del interesado, 
no sólo en la vista oral, sino en todas las fases del procedimiento; b) el derecho a la información y acceso a los archivos administrativos; e) el derecho a una instrucción adecuada y transparente del proceso; d) el derecho a la asistencia letrada, y e) el derecho a la motivación de la decisión del procedimiento. Desde el punto de vista procesal la realización de los derechos fundamentales requiere unas estructuras organizativas que aseguren: a) el pluralismo; b) el respeto de las minorías; e) la neutralidad o imparcialidad, y d) la apertura de los procedimientos a las necesarias innovaciones. Se pretende, con todo ello, posibilitar formas de protección dinámica de los derechos fundamentales que permitan su pleno desarrollo y efectividad (Denninger, 1987, 268 ss.).

La importancia que revisten las normas de procedimiento, como signo emblemático de la peculiaridad de la tutela jurídica de los derechos de la tercera generación, a cuya garantía se encamina el habeas data, se halla también corroborada por la difusión creciente de instituciones de protección que tiende a completar la función de garantía de los tribunales. En este sentido, debe hacerse notar el protagonismo adquirido por el sistema del Ombudsman en la defensa de los derechos y libertades de la tercera generación. Así, por ejemplo, pueden citarse una serie de variantes de Ombudsmen, unipersonales o colegiados, específicamente dirigidos a la protección de los ciudadanos respecto al tratamiento informatizado de datos personales; es decir, a hacer efectivo el habeas data. Cabe citar, entre tales instituciones, al Privacy Commissioner de Canadá y, en el ámbito escandinavo, al Datainspektionen sueco, al Registertylsynet danés, y al Datatilsynet noruego. En la república Federal de Alemania actúan, a escala federal y en los Ldnder que cuentan con leyes propias de protección de datos, los comisarios para la protección de datos (Datenschutzbeauftragten). En Francia, a partir de su Ley sobre Informática, Archivos y Libertades de 1978, se creó una Commission Nationale de J' Informatique et des Libertés compuesta por 17 miembros y con algunas competencias similares a las de la figura del Mediateur (institución francesa equivalente al Omhudsman respecto a la vigilancia de los departamentos administrativos informatizados. También Gran Bretaña cuenta con instituciones como el Registrar y el Data Protection Tribunal especializadas en la tutela de los derechos cívicos frente a eventuales abusos informáticos. La necesidad de crear una institución garante de los datos personales fue establecida como obligatoria para todos los países integrados en la Unión Europea, a partir de la Directiva 95/46 de Protección de Datos Personales. 
En España, tras la promulgación de la Ley Orgánica 5/1992, de 29 de octubre, de Regulación del Tratamiento Automatizado de los Datos de Carácter Personal (LORTAD) se creó la Agencia de Protección de Datos, cuya estructura y funciones se han mantenido en la vigente Ley Orgánica 15/1999, de 13 de diciembre, de Protección de Datos de Carácter Personal (LOPRODA), en la que se produjo la adaptación a nuestro sistema jurídico de las previsiones establecidas en la mencionada Directivade la UE, existiendo también Agencias de Protección de Datos en algunas Comunidades Autónomas. Estas Agencias tienen especial importancia para el ejercicio de la acción de habeas data, actuando como una jurisdicción de primera instancia para la sustanciación de esos procedimientos (Martín Casallo, 1994, 1ss.),

2) Se ha tenido ocasión de aludir reiteradamente al objeto del habeas corpus, consistente en la exhibición, manifestación o presentación de la persona detenida ante el juez. En lo que respecta al habeas data, el objeto se circunscribe a la presentación ante el ciudadano de los datos personales que le conciernen. En ello se cifra la facultad de acceso a sus informaciones personales, que constituye el núcleo o contenido del habeas data.

A fin de precisar dicho objeto o contenido, con referencia al habeas data, resulta oportuno recordar que la Ley Orgánica 15/1999, de 13 de diciembre, de Protección de Datos de Carácter Personal (LOPRODA), establece en su artículo 3 que se entenderá por datos de carácter personal: «cualquier información concerniente a la personas físicas identificadas o identificables.

3) Por lo que respecta a su finalidad, resulta evidente que en el habeas corpus se persigue garantizar el derecho fundamental a la libertad física de las personas; mientras que en lo que atañe al habeas data, su dimensión teleológica se cifra en la defensa del derecho fundamental a la libertad informática o facultad de autodeterminación informativa.

En nuestro ordenamiento jurídico, ese derecho fundamental se halla proclamado en el artículo 18.4 de nuestra vigente Constitución. La mencionada Ley Orgánica 15/1999 (LOPRODA), al desarrollar dicho artículo constitucional, establece que su finalidad será la de: «garantizar y proteger, en lo que concierne al tratamiento de los datos personales, las libertades públicas y los derechos fundamentales de las personas físicas, y especialmente de su honor e intimidad personal y familiar (art.1). 
Las generaciones de derechos humanos no entrañan un proceso meramente cronológico y lineal. En el curso de su trayectoria se producen constantes avances, retrocesos y contradicciones que configuran ese despliegue como un proceso dialéctico. Las generaciones de derechos humanos no implican, por tanto, la sustitución global de un catálogo de derechos por otro; en ocasiones, se traduce en la aparición de nuevos derechos como respuesta a nuevas necesidades históricas, mientras que, otras veces, suponen la redimensión o redefinición de derechos anteriores para adaptarlos a los nuevos contextos en que deben ser aplicados. De ahí, que la aparición del habeas data no pueda entenderse como una sustitución del habeas corpus, cuya función para la defensa de la libertad física sigue siendo plenamente vigente y mantiene intacta su importancia, sino que se trata de una garantía para nuevas agresiones a otras facetas de la libertad (Perez Luño, 2006, 43-44; 2012).

\section{LA PROTECCIÓN JURISDICCIONAL DE LAS LIBERTADES EN LA SOCIEDAD TECNOLÓGICA}

La complejidad de la vida en las sociedades con alto grado de desarrollo social y tecnológico ha determinado el crecimiento exponencial de los procesos, muchos de los cuales afectan directamente a la protección jurisdiccional de los derechos y libertades (Cappelletti, 2010,17 ss.; Cascajo Castro, 1983, 779 ss.; García Belaunde, 2011, 11 ss.). La masificación de los procesos judiciales constituye uno de los síntomas de los ordenamientos jurídicos de las sociedades avanzadas de nuestro tiempo. Consiguientemente se ha producido una mudanza en profundidad de la propia imagen del juez y del secretario judicial. Frente al carácter artesano que caracterizaba el quehacer del juez y del personal de los juzgados en el pasado, emerge ahora una Oficina Judicial con amplia presencia de métodos tecnológicos que requieren un personal familiarizado y cualificado para su correcta utilización.

Para responder a esos nuevos retos, en los últimos años, se han desarrollado una serie de aplicaciones tecnológicas destinadas a adecuar los instrumentos de la gestión de la Oficina Judicial a los apremios de nuestra época; es decir, a encauzarlas desde el artesanado a la segunda revolución industrial.

Conviene tener presente que esas proyecciones tienen aquí un sentido especial: frente al carácter prevalentemente teórico que revisten en otros sectores de la actividad jurídica, aquí entrañan 
una dimensión inequívoca normativa. Se trata de aplicaciones que no tienden sólo a permitir el conocimiento del Derecho aplicable, a discernir interpretaciones posibles, o a simular decisiones, sino que la informática jurídica judicial contribuye a la formación de los distintos momentos del iter procesal que tiene su conclusión en un acto normativo: la sentencia. Por eso estas aplicaciones informáticas constituyen una manifestación de lo que los anglosajones denominan Law in Action, es decir, del Derecho operativo y actuante

Pero, por ello, por ser procedimientos tendentes a la formación de normas, estas proyecciones de la Informática jurídica deben hallarse estrictamente regladas por el Derecho procesal informático para la plena garantía de la seguridad jurídica y de los derechos fundamentales (Álvarez-Cienfuegos, 1987-88, 469 ss.; Carrascosa López, 1994, 1045 ss.).

Debe señalarse que en el ámbit judicial, las aportaciones informáticas de documentación y de gestión avanzaron de forma paralela y simultánea. La proyección de la Informática Documental en la esfera de la Administración de Justicia, ha sido la respuesta a los graves problemas de hipertrofia normativa que aquejan a los ordenamientos jurídicos actuales. En estas circunstancias el acceso del juez a sistemas adecuados de documentación jurídica informatizada resulta del todo imprescindible. La inflación normativa es un fenómeno característico de las sociedades tecnológicamente avanzadas del presente. Esa situación se ha visto acompañada del grave menoscabo de la propia estructura formal de las normas legales. La certeza del Derecho, en cuanto posibilidad real de sus destinatarios de conocer y cumplir sus prescripciones, se ha resentido del aluvión normativo y de su continua modificación, pero en grado no menor de la prolijidad, complejidad y equivocidad del lenguaje en el que se hallan expresadas las disposiciones legales. En esas circunstancias no son sólo los ciudadanos, sino incluso el mismo legislador y los juristas -funcionarios administrativos, jueces o abogados- tienen graves dificultades para conocer y aplicar el Derecho.

La incesante promulgación de normas legales, la multiplicidad de decisiones jurisprudenciales, pertenecientes a distintas instancias y a tribunales nacionales, extranjeros e internacionales, cuyo exacto y puntual conocimiento es imprescindible para el funcionamiento correcto de la judicatura y para la consiguiente garantía de los derechos fundamentales, hace casi imposible su conocimiento y aplicación por los propios magistrados. Con esta nueva situación se pone en peligro el valor de la seguridad jurídica, al existir dificultades para conocer las normas aplicables vigentes en cada sector del ordenamiento jurídico. Ello trae como consecuencia el que, en ocasiones normas legales o 
jurisprudenciales aplicables a un determinado caso relativo a las libertades, sean ignoradas por quienes tienen el deber de desarrollar la función judicial, a través de la proyección sobre los casos concretos de esas fuentes jurídicas vigentes (Pérez Luño, 1994, 61 ss.).

Ante esa situación se hace apremiante la búsqueda de soluciones que restituyan la seguridad jurídica amenazada y que contribuyan a la eficaz garantía procesal de las libertades. Entre ellas, se debe recurrir por sus posibilidades en la información y en la gestión de documentación jurídica a la Informática jurídica documental y de gestión. Estas ayudas instrumentales tienen un espacio de aplicación, de especial importancia, en el ámbito de la Administración de Justicia que tiene por misión principal tutelar los derechos y libertades de los ciudadanos.

Pese a sus incuestionables ventajas la informatización documental judicial tiene determinados riesgos, que conviene prevenir, de modo que nunca resulten lesivos para la defensa de las libertades. Deberá garantizarse, en primer término, la calidad de los datos jurídicos almacenados, lo que equivale a proteger la veracidad $\mathbf{y}$ objetividad de la información seleccionada, así como la mayor exhaustividad posible de la misma y su continua actualización. Se precisan también medidas cautelares que velen por la seguridad de los datos almacenados (storage) para evitar la destrucción accidental, o la cancelación no autorizada, la pérdida, o la manipulación de las informaciones jurídicas. Estas garantías, comunes al funcionamiento de cualquier banco de datos, asumen especial trascendencia en el sector judicial, por la relevancia política, económica, social y cultural que reviste la documentación en los procedimientos judiciales. Es fácil imaginar, en efecto, las repercusiones de un servicio de documentación judicial automatizada que omitiera, intencional o deliberadamente, una determinada orientación o línea jurisprudencial o de la doctrina jurídica, para la aplicación del Derecho. De ahí, que la aspiración a la exhaustividad de la documentación judicial no constituya un mero requisito del correcto funcionamiento técnico de los Tribunales, sino una garantía de su transparencia e imparcialidad. Por esta misma razón, en los sistemas de teledocumentación judicial que utilizan abstracts o resúmenes, la infidelidad de su contenido puede producir un efecto en cadena, que multiplique la gravedad de sus consecuencias (Ocaña Lacalle, 2007, 67 ss.).

\section{CONCLUSIÓN}

En las reflexiones que anteceden, se ha tratado de exponer, sumariamente, algunas de las aportaciones que el Derecho procesal puede ofrecer para la garantía de los derechos y libertades en las 
sociedades tecnológicas. Se ha hecho especial referencia al papel que incumbe a la acción procesal del habeas data para la tutela de esa esfera de la intimidad que corresponde a los datos personales. La aspiración al reconocimiento de nuevas modalidades de garantía de los derechos humanos amenazados por los actuales instrumentos de control que son propios de las sociedades tecnológicas, sólo puede alcanzar plena satisfacción cuando logra traducirse en adecuados cauces de tutela, entre los que el habeas data posee un interés incuestionable.

Se ha puesto de relieve también, que la difusión de las NT y las TIC en las sociedades actuales, es un fenómeno ambivalente. En su reverso, plantea riesgos para las libertades que exigen renovadas formas de tutela procesal; pero, en su anverso, aportan nuevos mecanismos que refuerzan la operatividad de la documentación y la gestión judiciales $\mathrm{y}$, por consiguiente, representan un aumento de la eficacia de las instancias procesales que garantizan los derechos humanos.

La correcta implementación de los medios procesales dirigidos a responder a las amenazas tecnológicas contra la libertad, así como la correcta organización de los sistemas tecnológicos de documentación y gestión de la justicia, constituyen, por tanto, el horizonte de los actuales rumbos del Derecho procesal.

\section{BIBLIOGRAFÍA}

ÁLVAREZ-CIENFUEGOS, José María, «La informática en el ámbito de la Administración de Justicia», en Actualidad Informática Aranzadi , n. 4, 1992.

ARENAS RAMIRO, Mónica, El derecho fundamental a la protección de datos personales en Europa, Tirant lo Blanch, Valencia, 2006.

CAPEEPLETTI, Mauro, La jurisdicción constitucional de la libertad, trad. cast., de Héctor Fix-Zamudio, Palestra, Lima, 2010.

CARRASCOSA LÓPEZ, Valentín, "La gestión automatizada en el ámbito de la Justicia Española, en Informática y Derecho, n.5, 1994.

CASCAJO CASTRO, José Luis, «La tutela judicial reforzada de los derechos fundamentales y libertades públicas; los primeros recursos de amparo constitucional «, en el vol.col., El poder judicial, Instituto de Estudios Fiscales, Madrid, 1983.

DENNINGER, Erhard, «El derecho a la autodeterminación informativa, trad. cast. de A. E. Pérez Luño, en el vol. col. Problemas 
actuales de la documentación y la informática (Actas del Coloquio Internacional celebrado en la Universidad de Sevilla, 5 y 6 de marzo de 1986), a cargo de Pérez Luño, Antonio Enrique,Tecnos/ Fundación Cultural Enrique Luño Peña, Madrid, 1987.

FLORES DAPKEVICIUS, Rubén, Amparo, habeas corpus y habeas data, Faira Editor, Montevideo-Buenos Aires, 2011.

FROSINO, Vittorio, Cibernética, derecho y sociedad, trad. cast. de Salguero-Talavera, Carlos y Soriano, Ramón, con Prólogo de Pérez Luño, Antonio Enrique, Tecnos, Madrid, 1982.

GARCÍA BELAUNDE, Domingo, El Derecho Procesal Constitucional, Adrus, Lima 2011.

GARRIGA DOMÍNGUEZ, Ana, La protección de los datos personales en el Derecho español, con Prólogo, de Pérez luño, Antonio Enrique, Universidad Carlos III \& Dykinson, Madrid, 1999.

JELLINEK, George, System der subjektiven offentlichen Rechte, reimp. de la ed. de 1919, Scientia, Aalen, 1964.

LUCAS MURILLO DE LA CUEVA, Pablo, El derecho a la autodeterminación informativa, Tecnos, Madrid, 1990.

MARTÍN CASALLO, José, «Agencia de Protección de Datos: qué es y qué finalidad persigue, en Actualidad Informática Aranzadi, 1994, n.13.

MÁRTÍN OSTOS, José, «El procedimiento de habeas corpus, en La Ley, 1983, n.766, de 16 de septiembre.

MARTÍNEZ MORAN, Narciso, (ed.), Biotecnología, Derecho y dignidad humana, Comares, Granada, 2003.

OCAÑA LACALLE, Daniel, "Los archivos judiciales ante el Reto de las Nuevas Tecnologías, en el vol., sobre: Los Archivos Judiciales en la Modernización de la Administración de Justicia, (Congreso de Archivos Judiciales, Sevilla, 16,17 y 18 de mayo 2007), Consejería de Justicia y Administración Pública de la Junta de Andalucía, Sevilla, 2007.

PEREZ LUÑO, Antonio Enrique, «Intimidad y protección de datos personales: del habeas corpus al habeas data», en Estudios sobre el derecho a la intimidad, ed. a cargo de García San Miguel, Luis, Tecnos, Madrid, 1992; id., "Del Habeas Corpus al Habeas Data», en el vol. col. Encuentros sobre Informática y Derecho 1990-1991, ed. a cargo de Davara, Miguel Angel, Universidad Pontificia de Comillas, Madrid \& Aranzadi Editorial, Pamplona. 
PÉREZ LUÑO, Antonio Enrique, La seguridad jurídica , Ariel,

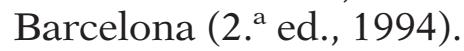

PÉREZ LUÑO, Antonio Enrique, La tercera generación de derechos humanos, Thomson/Aranzadi, Cizur Menor (Navarra), 2006.

PÉREZ LUÑO, Antonio Enrique, Los derechos humanos en la sociedad tecnológica, Universitas, Madrid, 2012.

PÉREZ LUÑO, Antonio Enrique, LOSANO, Mario Y GUERRERO MATEUS, María Fernanda, Libertad informática y leyes de protección de datos personales, Centro de Estudios Constitucionales, Madrid, 1989.

RODRÍGUEZ PALOP, María Eugenia, La nueva generación de derechos humanos. Origen y justificación, Dykinson, Madrid, 2. ${ }^{a}$ ed., 2010.

SAGÜES, Pedro, «Amparo informativo», en La Ley, (ed, Argentina), 1991.

SORIANO, Ramón, El derecho de habeas corpus, con Prólogo de A.E. Pérez Luño, Monografías del Congreso de los Diputados, Madrid, 1986. 